\title{
A TECNOLOGIA DA INFORMAÇÃO E COMUNICAÇÃO (TIC): FATOR CONDICIONANTE DA INOVAÇAO EM BIBLIOTECAS UNIVERSITÁRIAS
}

\author{
INFORMATION TECHNOLOGY AND COMMUNICATION TECHNOLOGY (ICT): \\ CONDITIONING FACTOR OF INNOVATION IN UNIVERSITY LIBRARIES
}

Rejane M. R. Ribeiro ${ }^{1}$

\section{RESUMO}

Aborda sobre as inovações em serviços e produtos ocorridas nas Bibliotecas Universitárias (BUs) devido à adoção de novas tecnologias de informação e comunicação (TIC). Apresenta a mudança do perfil do bibliotecário e identifica as competências necessárias para que este profissional possa acompanhar e gerenciar essas tecnologias.

\section{PALAVRAS-CHAVE}

Tecnologia da informação e comunicação. Bibliotecas universitárias.Inovação.

\section{ABSTRACT}

Addresses on innovations in products and services that occurred in University Libraries (BUs) due to the adoption of new information and communication technologies (ICTs). Presents the changing profile of librarians and identifies the skills required for these professionals to monitor and manage these technologies.

\section{KEYWORDS}

Information technology and communication. University libraries. Innovation.

\section{INTRODUÇÃO}

As Bibliotecas Universitárias (BUs) são tradicionalmente conceituadas "como bibliotecas de instituição de ensino superior (IES), destinadas a suprir as necessidades informacionais da comunidade acadêmica no desempenho de suas atividades de ensino, pesquisa e extensão" (PINTO, 1993, p.85). Fornecendo suporte informacional às atividades realizadas

\footnotetext{
${ }^{1}$ Bacharela em Biblioteconomia e Documentação pela Universidade Federal da Bahia. Especialista em Instituições de Ensino Superior. Especialista em Metodologia do Ensino Superior. Cursando Especialização em Gestão da Inovação Tecnológica. E-mail: rribeiro@uefs.br. 
pelas universidades, as bibliotecas ao longo do tempo foram celeiros de novas tecnologias, passando do pergaminho ao CD-ROM, das fichas perfuradas ao catálogo on line, das estantes em madeira as bases e bancos de dados.

Assim, a tecnologia sempre esteve no cotidiano das BUs, contudo tecnologia da informação e comunicação (TIC) presente no domínio coletivo como a tecnologia provida por recursos computacionais entrou na vida das BUs a partir do século XX. De acordo com Tigre (2005, p.206) “O microprocessador desenvolvido pela Intel em 1971, mudou a trajetória tecnológica mundial até então apoiada no uso intensivo de energia e materiais." O computador passa a fazer parte da realidade de indústrias, empresas com e sem fins lucrativos, lares etc., aperfeiçoando e agilizando atividades repetitivas, cansativas e que demandavam muito tempo.

Uma nova realidade então deslancha. Segundo Tigre (2005, p.207) "O aperfeiçoamento do computador em um único chip abriu caminho para uma onda de inovações complementares e convergentes, cujo ápice pode ser o advento da Internet, e do comércio eletrônico, que revolucionaram a organização do sistema produtivo".

As BUs diante desta nova realidade e do fato de que o mundo está condicionado pela continuidade nas mudanças e que para mudar é preciso inovar investiu e está investindo em tecnologia de informação e comunicação.

\section{INOVAÇÃO TECNOLOGICA}

Tecnologia pode ser definida segundo Tigre (2006, p.72) "como conhecimento sobre técnicas, enquanto as técnicas envolvem aplicações desse conhecimento em produtos, processos e métodos organizacionais." Já a inovação é algo novo ou alguma mudança em produtos, processos e métodos. O Manual de Oslo (2005) conceitua a inovação como:

\footnotetext{
... a implementação de um produto (bem ou serviço) novo ou significativamente melhorado, ou um processo ou um novo método de marketing, ou um novo método organizacional nas praticas de negócios, na organização do local de trabalho ou nas relações externas, assim o requisito mínimo para se definir uma inovação é que o produto, o processo, o método de marketing ou organizacional sejam novos ou melhorados para a empresa. (p.20)
}

Assim inovação tecnológica não é algo novo e sim algo que vem ocorrendo acompanhando a passagem do tempo, entretanto só na década 60 do século XX apareceram as primeiras estatísticas sobre inovação tecnológica através do Manual Frascati da Organização para 
Cooperação e Desenvolvimento Econômico (OCDE) permitindo de acordo com Tigre (2006, p.71) a "criação de sistemas de indicadores de esforço de desempenho tecnológico" bem como consolidando "conceitos e definições sobre atividades de pesquisa e desenvolvimento (P\&D)." atividades fundamentais para que a inovação ocorra.

Em Bibliotecas Universitárias inovação e padronização acompanham sua história. A padronização é necessária para assegurar a qualidade em alguns serviços e para a troca de informação a exemplo da catalogação por cópia, onde se pode copiar a ficha catalográfica feita por uma biblioteca e disponibilizada em rede, porque perder tempo fazendo algo que alguém já fez? Isto não significa apenas copiar a ficha, é relevante que se façam alterações conforme a necessidade, os usuários e a área de atuação de cada biblioteca. Padronizar é necessário também para criar as normas de atendimento e empréstimo de materiais etc.

A padronização é e foi necessária para realizar inovações ocorridas nas bibliotecas a exemplo dos catálogos que passaram de anotações em fichas e destas para catálogos on line, todavia apesar da mudança de suporte, de melhorias os catálogos mantêm sua essência comprovando que para inovar não é preciso abandonar por completo a tecnologia anterior. Podese adotar uma inovação incremental, ou menor, que segundo Reis (2008, p.45) "é aquela representada pelas mudanças técnicas menores surgidas da acumulação de experiências, assim como as melhorias de produto e/ou processo introduzidos posteriormente à inovação original”.

As inovações incrementais são aquelas que podem ou não resultar de atividades de Pesquisa e Desenvolvimento, muitas delas são sugeridas por funcionários ou mesmo usuários. Sabemos que P\&D não é uma pratica em bibliotecas e que mesmo tendo sofrido algumas inovações radicais na maior parte do tempo são as incrementais que são introduzidas continuamente para melhoria e aperfeiçoamento de produtos e serviços. Comprovando a teoria de Schumpeter onde "inovações "radicais" engendram rupturas mais intensas, enquanto inovações “incrementais" dão continuidade ao processo de mudança”. (2005, p.32)

\section{TECNOLOGIA DA INFORMAÇÃO E COMUNICAÇÃO INOVANDO BIBLIOTECAS UNIVERSITÁRIAS}

Mudança é a palavra chave para sucesso desde o fim do século XX e já sabemos que para mudar é preciso inovar. O usuário não deseja inovações radicais, as incrementais já satisfazem o desejo por mudança. As Bibliotecas Universitárias estão conscientes desta nova característica do mercado e por disponibilizarem mais serviços que produtos, se pautam nas TICs 
para inovar e consequentemente oferecer mais e melhores serviços principalmente os de informação, seu ponto chave, sem esquecer os outros como os de lazer e entretenimento (sim se pode encontrar os dois em bibliotecas) a exemplo dos serviços de ação cultural.

Com o uso das TICs as bibliotecas inovaram produtos e serviços, a noção de valor agregado a informação ganha corpo, as bibliografias foram substituídas por bases de dados, os levantamentos bibliográficos feitos através da cópia xerográfica das fichas catalograficas são realizadas em poucos minutos em catálogos digitais, os boletins ou listas de novas aquisições agora são elaborados com ferramentas do software (sistema) de gerenciamento da biblioteca e disponibilizados pelo próprio sistema, a consulta ao catálogo, livros e periódicos eletrônicos podem ser feitos de qualquer lugar que tenha acesso a internet, suprimindo assim a distância entre a informação e seu usuário.

As BUs sempre tiveram problemas com a segurança do acervo, furtos de obras, capítulos ou paginas de livros e periódicos arrancadas, paginas rabiscadas são comuns, com a utilização das TICs esses problemas encontraram soluções através da colocação no acervo de etiquetas ou fitilhos magnéticos, que são desmagnetizados quando a obra é emprestada, se algum usuário tenta sair da biblioteca sem passar pelo empréstimo o portão eletrônico avisa. A colocação de monitoração eletrônica (câmaras de vídeo com exibição da imagem em monitores de computador) foi outro recurso eficiente para o problema de segurança do acervo.

Algumas BUs já adotam a RFID (identificação por radiofrequência) para segurança do seu acervo, entretanto de acordo com Gomes, Nogueira e Abrunhosa (2009, p.16-18) o RFID é bem mais versátil, ele pode ser estendido a outras áreas com o controle de acesso de usuários, o rastreamento de uma obra (localização rápida a uma obra em um acervo mediante um leitor portátil de RFID), inventário e organização de estantes, empréstimo e auto-empréstimo, devolução e auto-devolução de obras.

Essa nova tecnologia RFID que "emprega sinais eletromagnéticos em um espectro de transferência que abrange desde algumas centenas de $\mathrm{KHz}$, passando por 13,56 $\mathrm{MHz}$ ate chegar a alguns GHZ, dependendo da aplicação" (GOMES, NOGUEIRA, ABRUNHOSA, 2009, p.7) é um exemplo perfeito de como as TICs melhoraram e agilizaram os serviços em bibliotecas, um inventário em um acervo de cerca de 100.000 exemplares feito em semanas com a utilização da RFID pode ser executado em horas. 
De acordo com Santos (2004) as TICs mudaram todo o ciclo informativo, isto pode ser visto nos processos, atividades, custos etc. através do processamento automático da informação em grande velocidade, do registro e armazenamento de dados a baixo custo, acesso a informação à distância e principalmente avaliação e monitoramento de uso da informação. Fernandes e Alves (1992, p.72) (apud NEVES, 2006, p.2) afirmam que para se ter sucesso na adoção da tecnologia é preciso saber escolher e o saber usar ambos depende da assimilação de inovações tecnológicas, do alinhamento entre a tecnologia da informação e as estratégias do negócio, bem como de atitudes gerenciais e comportamentais voltadas para a inovação.

As Bibliotecas Universitárias diante aos fatores que condicionam a escolha da nova tecnologia adotada, devem estar atentas ao custo e opções disponíveis no mercado, não podem esquecer que as tecnologias possuem um ciclo de vida e o preço varia conforme o ciclo, a exemplo de um sistema de automação de bibliotecas que lançado no mercado (na primeira comercialização) tem um preço, depois de consolidado no mercado o preço é outro. Outro fator de adoção de uma nova tecnologia é a base instalada de usuários, quanto mais pessoas utilizam aquela tecnologia melhor trabalhar com ela, pois isto facilita negociações de insumos (melhorias, novas ferramentas etc) e troca de experiência entre os usuários. De acordo com Tigre (2006) quanto mais uma tecnologia é adotada mais ela é utilizada, mais se aprende sobre ela e mais ela é desenvolvida e melhorada.

A biblioteca também deve estar atenta ao aprisionamento tecnológico que é o processo segundo Santos (2001, p.62) de dependência decorrente da dificuldade associada a uma troca de tecnologia por outra devido ao alto custo e também a não compatibilidade entre elas. Sendo assim é importante antes de adquirir uma TIC consultar grupos de usuários, periódicos da área e o que esta sendo discutido nos eventos, pois são resultados de pesquisas ou relatos de experiências.

\section{O BIBLIOTECARIO DIANTE DAS TECNOLOGIAS DE INFORMAÇÃO E COMUNICAÇÃO}

Com a adoção das TICs as bibliotecas foram obrigadas a fazer uma flexibilização do trabalho e para isto foi necessário a renovação do perfil da formação do bibliotecário, já não basta graduados em Biblioteconomia, é preciso profissionais empreendedores, dinâmicos, com uma formação interdisciplinar, aberto a mudanças, com visão estratégica, um profissional que entenda a mudança ocorrida nos processos de trabalho. Para Amorim e Amaral (2010, p.9) o bibliotecário 
deve ter "destreza e conhecimentos em fontes de informação, proatividade, conhecimento em tecnologia da informação" como competências necessárias para uma atuação eficaz e eficiente deste profissional. Percebe-se então com isto uma redefinição do perfil de mão de obra qualificada.

Teixeira e Andrade (2010) deixam clara a preocupação das escolas de Biblioteconomia com as habilidades que os bibliotecários devem possuir no século XXI

\begin{abstract}
Atualmente, as escolas e cursos de biblioteconomia em todo pais colocam paradigmas nas habilidades desejáveis para os profissionais da informação neste século, como: serem pessoas dinâmicas, comunicativas, flexíveis, ousadas, integradoras, proativas, empreendedoras com visão de futuro sobre a implementação e apoio para o uso das tecnologias emergentes nas bibliotecas, coordenarem a integração de bases de dados à demanda de informação e usuário, interação nos serviços técnicos automatizados, alem do gerenciamento em todas as atividades de automação na unidade de informação. Neste contexto é relevante verificar na pratica biblioteconômica o que representam as TICs, sobretudo a internet. (p. 5)
\end{abstract}

Os bibliotecários e sua equipe precisam ter autonomia e iniciativa para tomar decisões diante de um problema evitando que o usuário passe por varias pessoas para resolver um problema ou que tenha que voltar em outra hora ou outro dia.

Este novo perfil da equipe de funcionários de uma BU é também uma inovação, os profissionais passaram de tecnicistas (organizadores da informação dentro de rigorosas normas e técnicas) para gerenciadores e produtores de informação criando informação através das bibliotecas digitais como o caso das Bibliotecas Digitais de Teses e Dissertações (BDTD), da alimentação de bases de dados, da organização de boletins eletrônicos com informações sobre serviços, produtos, eventos e acervos em bibliotecas etc.

De acordo com Maranhão et al. (2010, p.2) "As tecnologias da informação e da comunicação influenciaram diretamente os serviços de referencia virtual, possibilitando o surgimento de novos meios de interação”. Pessoa e Cunha (2007, p.69) Conceituam referencia virtual como o serviço de referencia "prestado via Internet, marcando uma evolução do serviço de referência tradicional. Esse serviço surgiu no final da década de 1980, quando se tornou comum a disponibilização dos catálogos das bibliotecas na rede, o que veio facilitar a localização de informações e documentos."

Como exemplos de novos meios de interação com o usuário têm os chats, as redes de relacionamento etc. Esses novos meios de interação propiciaram um aumento do fluxo de usuários naquelas bibliotecas que fazem parte de uma rede social de relacionamento (dados informais que circulam nos eventos de biblioteconomia) a exemplo do facebook, orkut, myspace, 
twitter etc, o que mostra uma mudança na forma de acesso a informação e frequencia as bibliotecas. O usuário nao precisa estar fisicamente na biblioteca para realizar uma pesquisa, consultar o catálogo, ler e postar no mural informativo.

É de conhecimento publico que adolescentes são adeptos da web e das redes de relacionamento, consequentemente para atrair e manter essa classe de usuários é preciso estar utilizando as mesmas ferramentas e suportes de acesso a informação e comunicação que eles, é necessário ter computadores com acesso a internet, realidade nas BUs, porém nao é o suficiente, a equipe deve estar aberta e capacitada para utilizar essas novas ferramentas. O sucesso da inovação em BUs vai depender da capacitação e postura do bibliotecário e sua equipe diante das tecnologias de informação e comunicação.

\section{CONSIDERAÇÕES FINAIS}

As novas tecnologias de informação e comunicação permitem varias formas de implantação e adaptação de produtos e serviços, estes novos ou melhorados passam uma imagem de inovação e dinamismo das Bibliotecas Universitárias. Essa imagem é fundamental para que as bibliotecas conquistem e mantenha seus usuários, tarefa nada fácil diante das opções e facilidades de pesquisa encontradas na internet.

Assim, através da adoção de tecnologia da informação e comunicação as Bibliotecas Universitárias tentam conciliar o paradigma da biblioteca de guarda e conservação do acervo para o paradigma atual da biblioteca de apropriação do conhecimento e gerenciamento do acesso a informação.

\section{REFERENCIAS}

AMORIM, I. R.; AMARAL, R. M. Perfil de competências necessárias a função biblioteconômica. In: SEMINARIO NACIONAL DE BIBLIOTECAS UNIVERSITARIAS, 16., 2010, Rio de Janeiro. Anais... Rio de Janeiro, RJ: UFRJ, 2010.

GOMES, G.; NOGUEIRA, I.; ABRUNHOSA, J. J. Tecnologia RFID sem mistérios: mitos e verdades sobre o seu uso em acervos bibliográficos \& documentais. Nova Friburgo: Exxito Brasil, 2009.

MANUAL de Oslo: diretrizes para coleta e interpretação de dados sobre inovação -. tradução Flávia Gouveia. 3. ed. Rio de Janeiro : FINEP, 2005. 183p. Disponível em <http://www.finep.gov.br/imprensa/sala_imprensa/manual_de_oslo.pdf $>$. Acesso em 27.01.2011. 
MARANHAO, A.M. N. et al. A experiência do Sistema de Bibliotecas da PUC-RIO no atendimento virtual via chat. In: SEMINARIO NACIONAL DE BIBLIOTECAS

UNIVERSITARIAS, 16., 2010, Rio de Janeiro. Anais... Rio de Janeiro, RJ: UFRJ, 2010.

NEVES, J. M. S. A implantação de tecnologias da informação como fator de competitividade nos sistemas produtivos e nos negócios. In: SIMPEP, 13.,2006, Bauru, Anais... Bauru: SIMPEP, 2006.

PESSOA, P.; CUNHA, M. B. Perspectivas dos serviços de referência digital. Informação \& Sociedade. João Pessoa, v. 17, n.3, p.69-82, set./dez. 2007. Disponível em:

< http://www.ies.ufpb.br/ojs2/index.php/ies/article/view/836/1587>. Acesso em 24.11.2011.

PINTO, V.B. Informação a chave para qualidade total. Ciência da Informação. Brasília, v.22, n.2, p.85. maio/ago 1993.

REIS, D. R. Gestão da inovação tecnológica. 2.ed. Barueri, SP: Manole, 2008.

SANTOS, E. M. Aprisionamento tecnológico: novos desafios da gestão das estratégias organizacionais na era da informação. Caderno de pesquisas em administração. São Paulo, v.8, n.01, p. 61-7, jan./mar. 2001

Fatores Condicionantes da Adoção da Informação pelas Organizações. 2004, 85p.

(Dissertação. Mestrado em Administração - Universidade Federal da Bahia).

TEIXEIRA, C.; ANDRADE, M. G. O uso da internet em bibliotecas universitárias: analisando o caso da Biblioteca Central da Universidade Federal do Maranhão. In: SEMINARIO NACIONAL DE BIBLIOTECAS UNIVERSITARIAS, 16., 2010, Rio de Janeiro. Anais... Rio de Janeiro, RJ: UFRJ, 2010.

TIGRE, P. B. Gestão da inovação: a economia da tecnologia no Brasil. Rio de Janeiro: Elsevier, 2006.

Paradigmas tecnológicos e teorias econômicas da firma. Revista Brasileira de Inovação, v.4, n.1, jan/jun. 2005. 